\title{
Microstructure Refinement and Void Evolution via Friction Stir Processing of AA 5052
}

\author{
M. Adams-Hughes ${ }^{1}$, P. N. Kalu ${ }^{1}$, M. K. Khraisheh ${ }^{2}$, and N. Chandra ${ }^{1}$ \\ ${ }^{1}$ Dept of Mechanical Engineering, FAMU-FSU College of Engineering, Tallahassee, FL \\ 32310 \\ ${ }^{2}$ Dept of Mechanical Engineering, University of Kentucky, Lexington, KY 40506-0108
}

Superplastic forming allows complex geometries to be formed without welding and fastening devices. This fabrication method has been credited for reducing waste, weight and cost. An important criterion for enhancement of superplasticity is grain refinement. Finer grain size increases the optimum strain rate (for faster forming) and strain rate sensitivity (for increased ductility) and reduces the temperature at which optimum superplastic forming is achieved (reduced energy requirement). Grain refinement can be achieved by either thermo-mechanical processing or advanced severe plastic deformation processes, which include torsional strain severe plastic deformation, equal channel angular extrusion and friction stir processing. Friction Stir Processing (FSP) is less complex and less expensive when compared to thermo-mechanical processing and it is not limited to a small processing area as are equal channel angular extrusion and torsional strain severe plastic deformation. Furthermore, it can be confined to specific region of a material.

Friction Stir Processing is a relatively recent technique for localized grain refinement and is based on the well-established Friction Stir Welding (FSW) method. Friction Stir Processing uses a wear resistant, rapidly rotating cylindrical tool with a pin that extends from the shoulder. The tool is driven up to the shoulder into the plate (or sheet) and traversed in the desired direction. The energy generated by friction softens the material below the melting point. The plastically deformed material is then moved from the leading edge to the trailing edge of the tool as it moves. The technique is considered solid state since no molten material is formed in the process [1,2]. FSP can be accomplished using rather simple tools (i.e. milling machine, SP tool, simple backing plate).

For this study a single sheet of AA 5052 is friction stir processed as described above. The samples were then characterized using orientation imaging microscopy (OIM). The locations of the samples studied are as shown in schematic of Figure1. Our research has shown that the amount of grain refinement achieved is dependent on, but not limited to, the processing parameters (rotation and translation speeds). A decrease in rotation and translation speed results in a decrease in grain size. Starting with a grain diameter of 13.41 microns in the as-received material, FSP can produce grain diameters in the nugget zone from 4.49 microns at $1000 \mathrm{rpm}$ and $2.5 \mathrm{ipm}$ to as small as 0.72 microns at $600 \mathrm{rpm}$ and $2 \mathrm{ipm}$. Due to the complexity of the microstructure produced by FSP it should be noted that there is a change in grain size as well as texture from the unprocessed zone to the nugget zone (see Figure 2). It was also established that the volume fraction of voids present in the processed sample depended on the rotation and translation speeds. OIM has proven to be a very useful tool in understanding the microstructure and void evolution in 
a material (AA 5052) that is usually difficult to characterize using other typical methods (e.g. optical microscopy or scanning electron microscopy).

\section{References}

[1] C.M. Chen, R. Kovacevic, International Journal of Machine Tools \& Manufacture 43 (2003) 1319-1326.

[2] M. Peel, A. Steuwer, M. Preuss, P.J. Withers, Acta Materialia 51 (2003) 4791-4801.

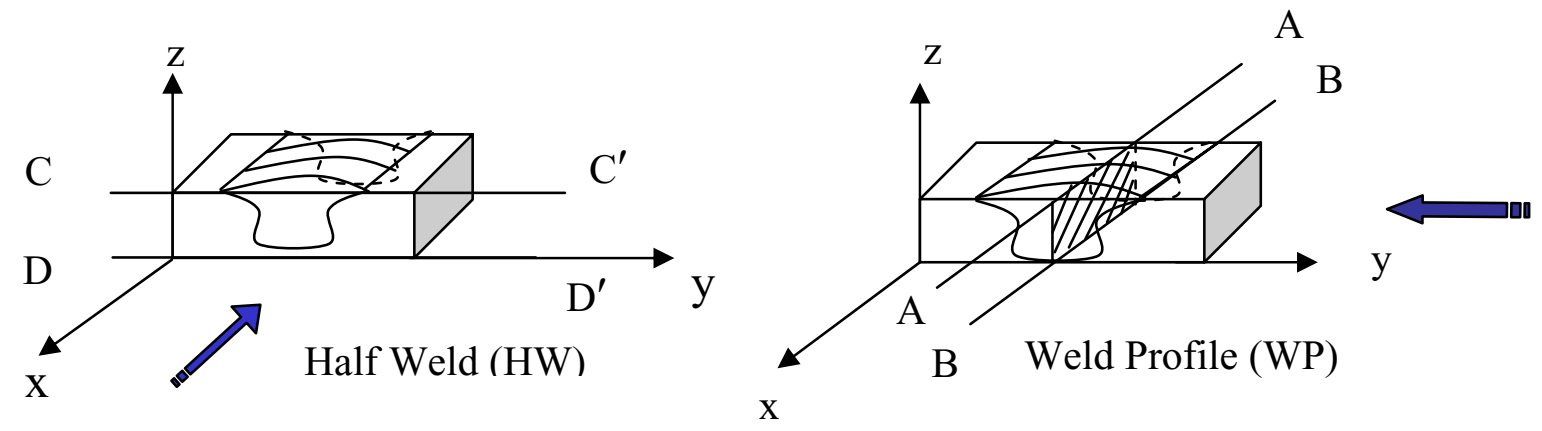

Figure 1. Shows the location from which the samples were taken for OIM analysis.
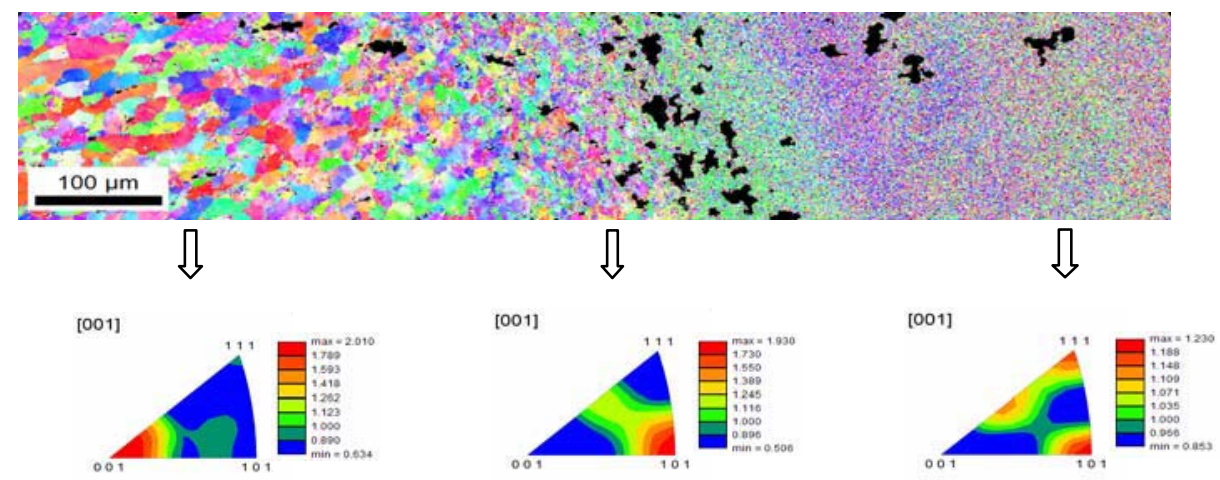

(a)
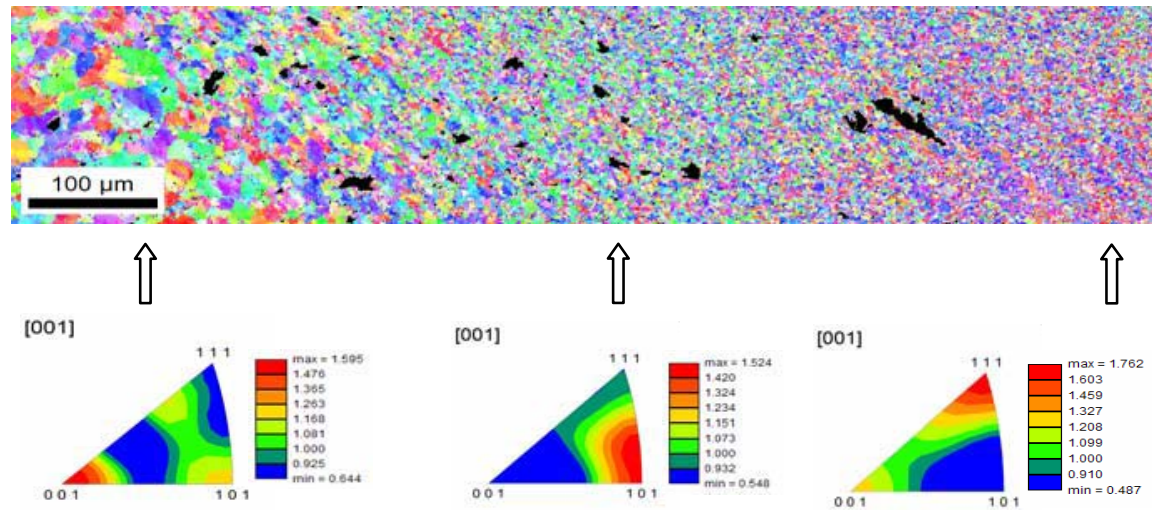

Figure 2. Shows the friction stir processed zones for (a) $600 \mathrm{rpm} 2 \mathrm{ipm}$ and (b) $800 \mathrm{rpm} 2 \mathrm{ipm}$. The unprocessed zone is at the left and the nugget zone is at the right. 